\title{
A Proposed Relationship between Time and Load to Quantify Fatigue
}

\author{
Shaheen Ahmed, Dept. of Computer Information Systems and Technology, \\ The University of West Alabama, Station 24, 109 Guy Hunt, Livingston, AL 35470, USA \\ Kari Babski-Reeves, Dept. of Industrial and Systems Engineering, \\ Mississippi State University, 260I McCain Eng. Building, Mississippi State, MS 39762, USA \\ Janice DuBien, Dept. of Mathematics and Statistics, \\ Mississippi State University, 448 Allen Hall, Mississippi State, MS 39762, USA \\ Heather Webb, Dept. of Kinesiology, \\ Mississippi State University, 121 McCarthy Gymnasium, Mississippi State, MS 39762, USA
}

\begin{abstract}
Research has shown that both workload and time are associated with fatigue; however, a functional relationship does not exist. This study observed sixteen participants in their workplace (computer programming and simulation) to quantify the workload-time-fatigue relationship for sedentary tasks. Equal numbers of participants were observed in the morning and afternoon sessions. Workload was measured both subjectively and objectively; while fatigue was measured using the Swedish Occupational Fatigue Inventory (SOFI) and a modified Borg scale. Forward selection stepwise regression analysis was performed to determine the underlying mathematical relationship between workload, time, and fatigue. Results indicate that for sedentary tasks, fatigue is a hyperbolic function of workload and time; meaning an inherent interactiononly relationship between workload, time, and fatigue exists. Therefore, an individual can work for longer periods of time if the workload is minimal, and vice versa.
\end{abstract}

\section{INTRODUCTION}

In the United States, $38 \%$ of workers reported fatigue, and $66 \%$ of those reported health-related losses of productive time compared with $26 \%$ of those without fatigue. Workers with fatigue cost employers $\$ 136$ billion annually, which is $\$ 101$ billion higher compared with workers without fatigue (Ricci, Chee, Lorandeau, \& Berger, 2007). The prevalence of fatigue is growing every year. For example, in The Netherlands, 50\% of women and $33 \%$ of men reported fatigue in the workplace in 2008 as compared to $38 \%$ of women and $24 \%$ of men 15 years before (Boksem \& Tops, 2008).

Fatigue has been reported at the end of a regular working day, and fatigue increases over time. Duration of work-tasks or amount of hours spent in the workplace is one of the primary factors affecting reported fatigue levels (El Falou et al., 2003; Jensen, 2003; Østensvik, Veiersted, \& Nilsen, 2009). Other factors, such as workload and sleep deprivation, have also been found to contribute to fatigue levels (Dorrian, Baulk, \& Dawson, 2011; Guastello et al., 2013; Hancock \& Desmond, 2001).

Numerous definitions and tools to measure fatigue, both subjectively and objectively, have been observed in the literature (Ahmed, 2013). Fatigue has also been observed to be measured both qualitatively and quantitatively (Ahmed, 2013). Neither a consensus definition of fatigue nor a precise method or tool for measuring fatigue has been universally adopted (Fukuda et al., 1994; Schwartz, Jandorf, \& Krupp, 1993; Shen, Barbera, \& Shapiro, 2006). Moreover, research describing the fundamental relationship between workload, time, and fatigue is not as clear as what factors contribute to the development of fatigue.

In the muscle fatigue literature, especially for localized fatigue, a well-accepted functional relationship exists between the endurance, time and muscle fatigue. Time interacts with load hyperbolically to affect muscle fatigue (Chaffin, 1973;
Fitts, 1994; Monod \& Scherrer, 1965). The research question here is, does this relationship hold for total or overall fatigue?

\section{Hypothesis}

The mathematical relationship of the resultant interaction for fatigue is hypothesized in Equation 1.

$$
x y=\text { constant }
$$

Where,

Equation 1

$x=$ time spent on work-tasks;

$y=$ fatigue load $=$ quantitative factors (e.g. change in rest-

ing heart rate, workload, daily sleep, etc.) that affect fatigue is defined as "fatigue load";

constant = iso-fatigue constant, which is fixed for a particular situation or working condition.

\section{METHODOLOGY}

\section{Experimental Design}

An observational study in the field was performed to evaluate fatigue in prolonged, mentally demanding work tasks. However, the strategy of data collection has resulted in a repeated measure design where participants were randomly selected, and each participant was measured over a four-hour time period. A fifteen-minute break was provided in the middle of the four hours.

\section{Independent Variable}

Time was studied as an independent variable in the research. The time variable consisted of ten levels, including assessments every thirty minutes and two baseline assessments at the beginning of each two-hour session. 


\section{Dependent Variable}

Multiple dependent measures, including both objective and subjective measures, were studied. The data collection, instrumentations and data cleaning procedures are discussed for each dependent variable in respective sections below. Two subjective instruments, the Modified Borg CR-10 scale (Borg Scale) and the Swedish Occupational Fatigue Inventory (SOFI), were used to measure participants' subjective perceptions of fatigue. NASA-TLX and change in heart rate were used as the subjective and objective measures of workload, respectively.

Modified Borg CR-10 scale to measure fatigue: Both the Rating of Perceived Exertion (RPE) scale and the Category Ratio (CR-10) scale have been widely used to measure both perceived exertion and overall fatigue (E. Åhsberg,

Gamberale, \& Gustafsson, 2000; G. Borg, 1970). A modified Borg CR-10 (modified because perceived overall fatigue was solicited instead of perceived exertion) scale was used to measure perceived fatigue every 30 minutes over a four-hour study period. A total of 10 assessments were performed including the baseline measurements at the beginning of each two-hour session before and after a short 15-minute break. Participants rated their perceived fatigue for specific body parts presented in random order. Perceived fatigue was collected for: (1) leg, (2) buttock, (3) lower back, (4) upper back (5) shoulder- neck, (6) eyes, and (7) whole body. A total fatigue score for each 30-minute block was calculated by adding fatigue ratings for each body part, including the whole body (Equation 2) (G. A. Borg, 1982; Loge, Ekeberg, \& Kaasa, 1998).

Fatigue Rating in Borg Scale (BORG)

$=$ Fatigue $_{\text {leg }}+$ Fatigue $_{\text {buttock }}+$ Fatigue $_{\text {lower back }}$

+ Fatigue $_{\text {upper back }}+$ Fatigue $_{\text {shoulder neck }}+$ Fatigue $_{\text {eye }}$ + Fatigue $_{\text {whole body }}$

Equation 2

Swedish Occupational Fatigue Inventory (SOFI): The short version of SOFI was used, and participants completed the survey every 30 minutes (Ahmed, 2013; Elizabeth Åhsberg, Garnberale, \& Kjellberg, 1997). A total multidimensional fatigue score for each 30-minute block was calculated by adding the fatigue ratings for five dimensions of SOFI (Equation 3) (E. Åhsberg, et al., 2000; Loge, et al., 1998).

\section{Fatigue Rating in SOFI Scale (SOFI)}

$=$ Fatigue $_{\text {physical exersion }}+$ Fatigue $_{\text {physical discomfort }}$

+ Fatigue $_{\text {lack of motivation }}+$ Fatigue $_{\text {sleepiness }}$

+ Fatigue lack of energy

Equation 3

Subjective measure of workload: Subjective perceptions of workload were measured using the NASA-TLX. While fatigue and workload are generally considered two distinctly different concepts, they have been found to be related in previous studies. A total workload score for each 30-minute block was measured by adding the scores for six dimensions of
NASA-TLX (Hart \& Staveland, 1988). Similar studies have not identified any significant difference between weighted and un-weighted scores of NASA-TLX(DiDomenico, 2003;

Ikuma, Nussbaum, \& Babski-Reeves, 2009). Therefore, simple un-weighted scores were used to calculate total workload measured by NASA-TLX (Equation 4).

Workload Rating in NASA (NASA) = Workload $_{\text {mental demand }}+$ Workload $_{\text {physical demand }}+$ Workload $_{\text {temporal demand }}+$ Workload $_{\text {effort }}+$ Workload $_{\text {performance }}+$ Workload $_{\text {frustration level }}$

Objective measures of workload: Change in heart rate was continuously collected over the four-hour study period (Duchon, Smith, Keran, \& Koehler, 1997). A Polar RS 400 heart-rate monitor (Polar Electro Oy, Professorintie 5, Fl90440 Kempete, Finland; www.polar.fi) was used to measure heart rate continuously at a sampling rate of $1 \mathrm{~Hz}$. Raw heart rate data was downloaded to the Polar Pro-Trainer 5 software (Polar Electro Oy, Professorintie 5, Fl-90440 Kempete, Finland; www.polar.fi) for analysis at a later time.

The heart-rate monitor was placed across the chest so that the sensor sits right of the sternum. A wrist watch was worn on either hand or placed on the working desk to minimize interference, but close enough to the chest sensor for continuous heart rate monitoring. To start the experiment, resting heart rate was calculated in a sitting position while participants were requested to sit back and relax until they reached a steady state resting heart rate defined to be 2 consecutive heart rate readings within $5 \mathrm{bpm}$. This procedure took 2 to 5 minutes. After recording resting heart rate, the heart rate wrist watch clock was started to begin the experiment. Average heart rate was also calculated during the steady state condition by collecting three heart rate readings. Change in heart rate $(\Delta \mathrm{HR})$ was used in all analyses. To compute $\Delta \mathrm{HR}$, the task heart rate was averaged for each 30-minute block and the resting heart rate was subtracted from the average, heart rate for the 30-minute block.

\section{Participants}

Sixteen self-reported healthy participants with no medical conditions (back pain, shoulder or neck pain, buttock pain, or headache) and 20/20 natural or corrected eye vision volunteered for the study. No other exclusion criteria were used. Overall demographic statistics are provided in Table 1.

Table 1. Overall demographic statistics

\begin{tabular}{llllll}
\hline & $\begin{array}{l}\text { Number of } \\
\text { Subjects }\end{array}$ & $\begin{array}{l}\text { Mean } \\
\text { Deviation }\end{array}$ & $\begin{array}{l}\text { Mini- } \\
\text { mum }\end{array}$ & $\begin{array}{l}\text { Maxi- } \\
\text { mum }\end{array}$ \\
\hline Age (years) & 16 & 28.69 & 4.43 & 23 & 39 \\
Sleep (hours) & 16 & 7.31 & 0.73 & 6.5 & 9.5 \\
Hours worked weekly & 16 & 46.88 & 8.48 & 30 & 60 \\
Total weekly working hours & 16 & 56.94 & 10.51 & 35 & 74 \\
in all occupations & & & & & \\
End of the day fatigue & 16 & 3.69 & 1.41 & 1 & 7 \\
Monday morning fatigue & 16 & 0.25 & 0.66 & 0 & 2 \\
Weekly exercise frequency & 16 & 2.25 & 1.61 & 0 & 4 \\
Daily rest after work (hours) & 16 & 2.44 & 0.61 & 1 & 3 \\
\hline
\end{tabular}




\section{Procedure}

Each participant was given a verbal and written description of the experiment and was required to complete an Informed Consent document approved by the Institutional Review Board (IRB) for Research Involving Human Subjects at Mississippi State University. Participants were asked to complete a demographic questionnaire after the informed consent procedure (summarized in Table 1). The heart-rate monitor was then attached according to manufacturer guidelines, and a resting heart rate assessment was conducted. At each 30minute interval within each two-hour testing block, the subjective fatigue and workload assessments were collected. After the end of the first two hours of testing, a 15-minute break was provided, and all measures were collected. Procedures for the first-two-hour test session were replicated for a second-twohour testing session.

\section{Data Analysis}

Stepwise regression was used to determine the relationship between time, load and fatigue. A significance level for entry and significance level to stay for the stepwise procedure was set to 0.15 (Kutner, 2005). Model performance was assessed by using adjusted $R^{2}$ values and other standard criteria (Kutner, 2005). The population model used to determine the hyperbolic relationship is given in Equation 5.

$$
Y=\beta_{0}+\beta_{1} T+\beta_{2} X_{2}+\beta_{12} T X_{2}+\varepsilon
$$

Equation 5

Where,

$\mathrm{Y}=$ Perceived fatigue measured either in Borg or SOFI;

$\beta_{0}=$ Intercept $\beta$ 's $=$ parameters; $\mathrm{T}=$ Time, the running clock during the experiment; $\mathrm{X}_{2}=\mathrm{A}$ factor that causes fatigue, for example workload; $\varepsilon=$ Error $\sim \mathrm{N}\left(0, \sigma^{2}\right)$, independent and identically distributed.

\section{RESULTS}

Based on the previous literature, it was hypothesized that workload, time and fatigue follow a hyperbolic functional relationship. To investigate this inherent relationship, stepwise regressions were performed using time, workload (increase in heart rate and workload measured in NASA-TLX) and their interaction as predictors of fatigue.

$\underline{\text { Table 2. Summary of stepwise regression }}$

\begin{tabular}{lllll}
\hline & Variable Entered & Model $R^{2}$ & F Value & Pr $>\mathrm{F}$ \\
\hline Borg & $\mathrm{T}^{*} \mathrm{NASA}$ & 0.43 & 118.40 & $<\mathbf{0 . 0 0 0 1}$ \\
Borg & $\mathrm{T}^{*} \Delta \mathrm{HR}$ & 0.39 & 100.16 & $\mathbf{0 . 0 0 0 1}$ \\
SOFI & $\mathrm{T}^{*} \mathrm{NASA}$ & 0.26 & 56.50 & $\mathbf{< 0 . 0 0 0 1}$ \\
SOFI & $\mathrm{T}^{*} \Delta \mathrm{HR}$ & 0.35 & 83.88 & $\mathbf{< 0 . 0 0 0 1}$ \\
\hline
\end{tabular}

$\mathrm{T}=$ Time in minutes, NASA=perceived workload measured in NASA-TLX and $\Delta \mathrm{HR}=$ change in resting heart rate.

The stepwise regression analysis results are given in Table 2 and Table 3. Only the interaction term between time and a factor (e.g. workload) that causes fatigue was kept by the stepwise regression analysis in all four cases (Table 2). Table 3 shows the parameter estimates and the associated statistical tests. All interaction terms were observed to be significant with p-value ranges between 0.02 and less than 0.0001 .

Table 3. Parameter estimates from the stepwise regression

\begin{tabular}{|c|c|c|c|c|c|c|}
\hline & & $\begin{array}{c}\text { Parameter } \\
\text { Estimate }\end{array}$ & $\begin{array}{l}\text { Standard } \\
\text { Error }\end{array}$ & $\begin{array}{c}\text { Type II } \\
\text { SS } \\
\end{array}$ & $\begin{array}{c}\mathrm{F} \\
\text { Value }\end{array}$ & $\begin{array}{l}\text { Pr } \\
>\mathrm{F}\end{array}$ \\
\hline \multirow[t]{2}{*}{ Borg } & Intercept & 2.122320 & 0.62277 & 315.05 & 11.61 & $\overline{0.0000}$ \\
\hline & $\mathrm{T}^{*} \mathrm{NASA}$ & 0.001670 & 0.00015 & 3211.99 & 118.40 & $<0.0001$ \\
\hline \multirow[t]{2}{*}{ Borg } & Intercept & 2.156460 & 0.66039 & 309.70 & 10.66 & $\overline{0.0000}$ \\
\hline & $\mathrm{T}^{*} \Delta \mathrm{HR}$ & 0.003270 & 0.00032 & 2909.16 & 100.16 & $<0.0001$ \\
\hline \multirow[t]{2}{*}{ SOFI } & Intercept & 1.516660 & 0.46807 & 160.89 & 10.50 & 0.0000 \\
\hline & $\mathrm{T} * \mathrm{NASA}$ & 0.000869 & 0.00012 & 865.86 & 56.50 & $<0.0001$ \\
\hline \multirow[t]{2}{*}{ SOFI } & Intercept & 0.995270 & 0.45173 & 65.97 & 4.85 & $\overline{0.0300}$ \\
\hline & $\mathrm{T}^{*} \Delta \mathrm{HR}$ & 0.002050 & 0.00022 & 1139.89 & 83.88 & $<0.0001$ \\
\hline
\end{tabular}

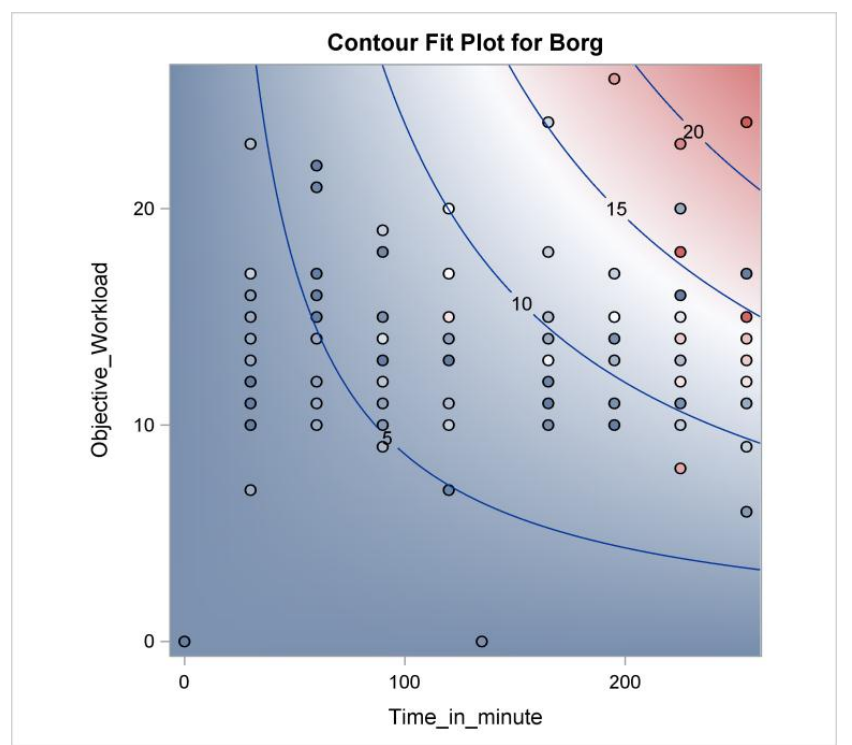

Figure 1. Visualization of the proposed hyperbolic relationship between the workload measured by change in resting heart rate and time to measure fatigue by Borg.

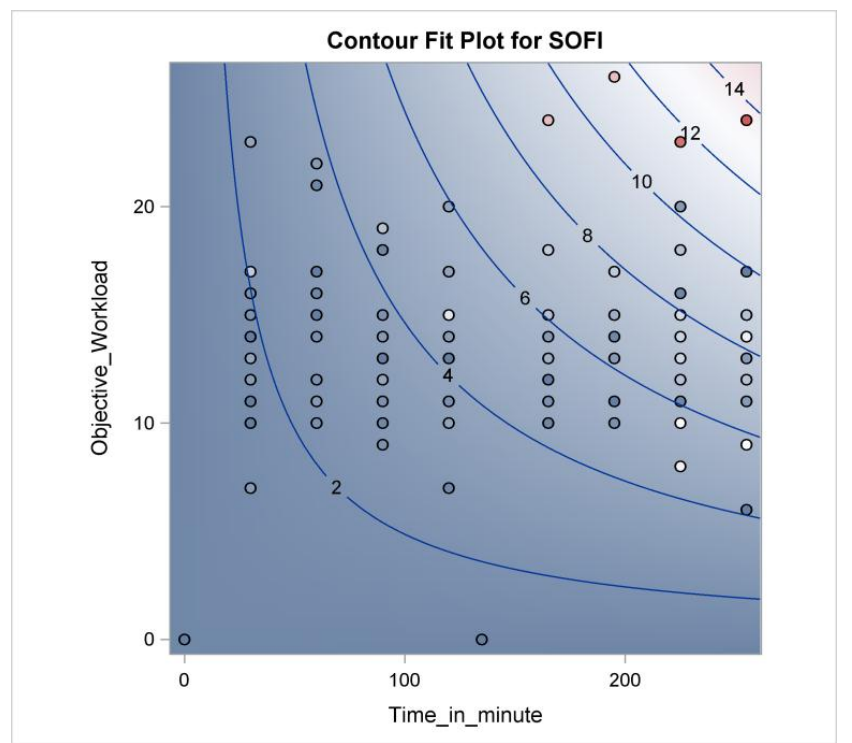

Figure 2. Visualization of the proposed hyperbolic relationship between the workload measured by change in resting heart rate and time to measure fatigue by SOFI. 
In Figure 1, Figure 2, Figure 3 and Figure 4, the color gradient on the response surface represents the increase in fatigue from blue to red. The stronger contrast between the color of the fitted surface and an observation indicates a higher residual at that point. The lines on these figures represent iso-fatigue curves; meaning that, for a particular combination of time and workload (measured either subjectively or objectively), fatigue will be constant. Only one fatigue value is perceived on a specific hyperbolic curve in the figures. All these figures indicate a perfect hyperbolic relationship as it has been observed in the stepwise regression analysis.

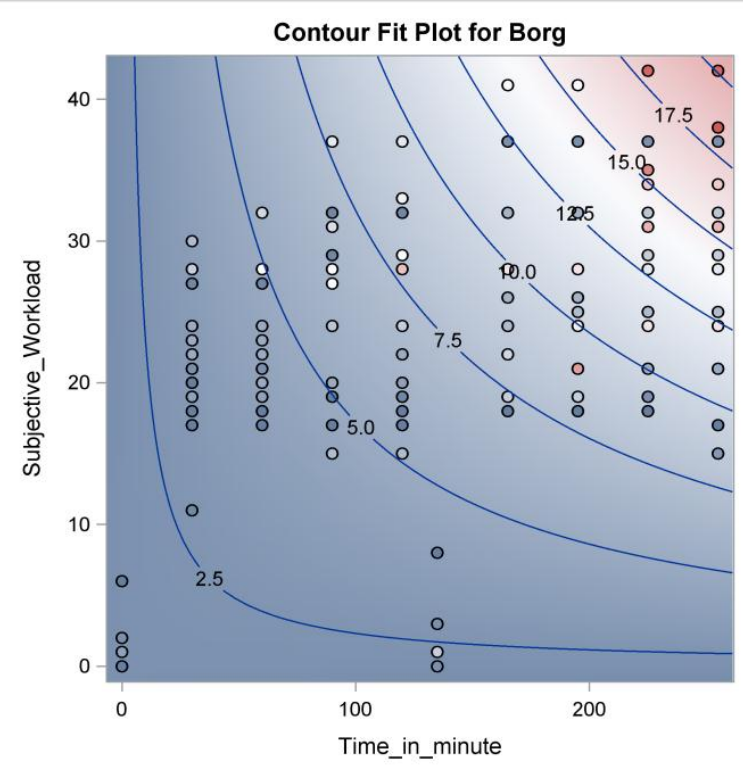

Figure 3. Visualization of the proposed hyperbolic relationship between the workload measured by NASA_TLX and time to measure fatigue by Borg.

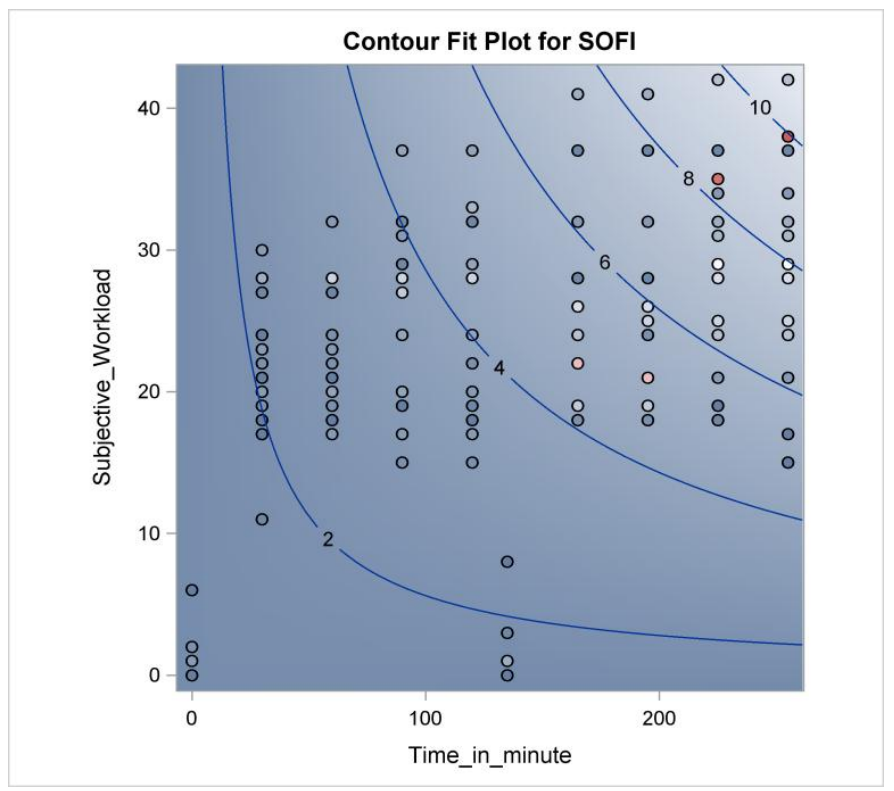

Figure 4. Visualization of the proposed hyperbolic relationship between the workload measured by NASA_TLX and time to measure fatigue by SOFI.

\section{DISCUSSION}

As expected, this study observed that fatigue increased over time. Interestingly, in the stepwise regression analysis process, time significantly interacted with workload in the study, indicating that the time trends in the fatigue measures are dependent on other factors. Similar to localized muscle fatigue curves (Rohmert's curves) (Edwards, 1981; Hill, Poole, \& Smith, 2002; Monod \& Scherrer, 1965), previous studies have hypothesized that there could be a possible hyperbolic relationship between time and workload (El Falou, et al., 2003; Jensen, 2003; Østensvik, et al., 2009). Moreover, in physical ergonomics, the standardized weight limits over time for manual material handling also provide an indication of the hyperbolic relationship proposed in this study (Snook \&

Ciriello, 1991; Snook \& Irvine, 1969). For example, the standardized data cleaning process for repeated measure cortisol hormone using the area under the curve over time (Pruessner, Kirschbaum, Meinlschmid, \& Hellhammer, 2003), which is basically the interaction between cortisol response and time that explains total fatigue.

This study has utilized two factors, including (1) change in resting heart rate and (2) workload measured by NASATLX, separately with time to determine the hyperbolic relationship between workload and time that explains total (overall) fatigue. In both cases, the only term left in the stepwise regression process was the interaction term, which could justify the possible hypothesized hyperbolic relationship between a workload and time to measure total fatigue. The estimated parameters were highly significant with $R^{2}$ values ranging from 0.22 to 0.43 . For a single variable to explain human fatigue, $R^{2}$ values could be considered good because of the complex nature of fatigue caused by many intrinsic and extrinsic factors (Di Milia et al., 2011).

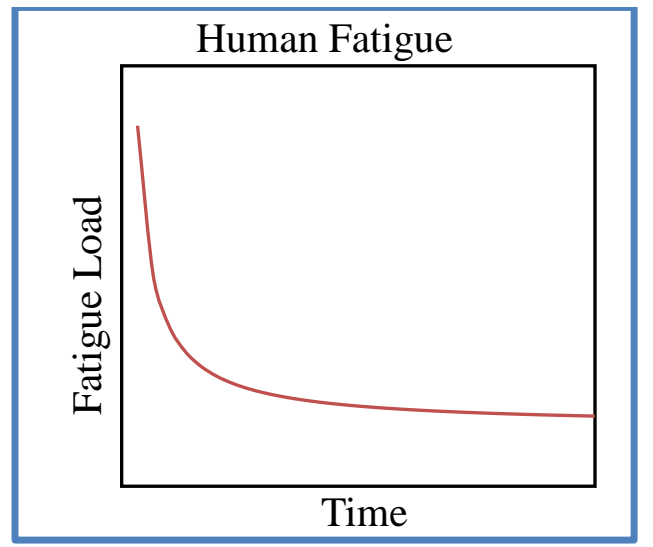

Figure 5. The proposed hyperbolic relationship between the workload and time to explain fatigue.

In this study, more interestingly, the asymptotes parallel to both axes indicate that an individual would not report fatigue for a long period of time if there were no workload. In contrast, an individual would report fatigue within a very short period of time if the workload were too high for that person. The observed hyperbolic relationship could be elaborated on 
as "the higher intensity of a workload induces fatigue quicker and vice versa." The relationship is depicted in Figure 5.

\section{CONCLUSION}

This study has utilized both subjective and objective measures of workload. Moreover, the perception of fatigue was obtained using single-dimension Borg and multidimensional SOFI scales to test the hypothesized mathematical relationship between workload and time that could be useful to measure fatigue in the workplace.

The findings of this study suggest that workload and time significantly interact to affect fatigue. Future studies should focus on these interactions, not just the time effect alone, because the main effect becomes less relevant when a significant interaction is presented.

\section{REFERENCES}

Ahmed, S. (2013). Human fatigue in prolonged mentally demanding work-tasks: an observational study in the field. Doctor of Philosophy Dissertation, Mississippi State University, Mississippi State.

Åhsberg, E., Gamberale, F., \& Gustafsson, K. (2000). Perceived fatigue after mental work: An experimental evaluation of a fatigue inventory. [print]. Ergonomics, 43(2), 252-268.

Åhsberg, E., Garnberale, F., \& Kjellberg, A. (1997). Perceived quality of fatigue during different occupational tasks Development of a questionnaire. International Journal of Industrial Ergonomics, 20(2), 121-135.

Boksem, M. A., \& Tops, M. (2008). Mental fatigue: costs and benefits. Brain Res Rev, 59(1), 125-139.

Borg, G. (1970). Perceived exertion as an indicator of somatic stress. Scandinavian Journal Of Rehabilitation Medicine, 2(2), 92-98.

Borg, G. A. (1982). Psychophysical bases of perceived exertion. Med Sci Sports Exerc, 14(5), 377-381.

Chaffin, D. B. (1973). Localized muscle fatigue-definition and measurement. Journal of Occupational and Environmental Medicine, 15(4), 346-354.

Di Milia, L., Smolensky, M. H., Costa, G., Howarth, H. D., Ohayon, M. M., \& Philip, P. (2011). Demographic factors, fatigue, and driving accidents: An examination of the published literature. Accident Analysis \&amp; Prevention, 43(2), 516-532.

DiDomenico, A. T. (2003). An investigation on subjective assessments of workload and postural stability under conditions of joint mental and physical demands. Virginia Polytechnic Institute and State University.

Dorrian, J., Baulk, S. D., \& Dawson, D. (2011). Work hours, workload, sleep and fatigue in Australian Rail Industry employees. Applied Ergonomics, 42(2), 202-209.

Duchon, J. C., Smith, T. J., Keran, C. M., \& Koehler, E. J. (1997). Psychophysiological manifestations of performance during work on extended workshifts. International Journal of Industrial Ergonomics, 20(1), 39-49.

Edwards, R. H. (1981). Human muscle function and fatigue. Human muscle fatigue: physiological mechanisms, 1-18.

El Falou, W., Duchêne, J., Grabisch, M., Hewson, D., Langeron, Y., \& Lino, F. (2003). Evaluation of driver discomfort during longduration car driving. Applied Ergonomics, 34(3), 249-255.

Fitts, R. (1994). Cellular mechanisms of muscle fatigue. Physiological reviews, 74(1), 49-94.

Fukuda, K., Straus, S. E., Hickie, I., Sharpe, M. C., Dobbins, J. G., \& Komaroff, A. (1994). The chronic fatigue syndrome: a comprehensive approach to its definition and study. Annals of internal medicine, 121(12), 953-959.

Guastello, S. J., Boeh, H., Gorin, H., Huschen, S., Peters, N. E., Fabisch, M., \& Poston, K. (2013). Cusp catastrophe models for cognitive workload and fatigue: a comparison of seven task types. Nonlinear dynamics, psychology, and life sciences, 17(1), 23-47.

Hancock, P. A., \& Desmond, P. A. (2001). Stress, Workload, and Fatigue: Lawrence Erlbaum Associates, Inc.

Hart, S. G., \& Staveland, L. E. (1988). Development of NASA-TLX (Task Load Index):results of empirical and theoretical research. In P. A. Hancock \& N. Meshkati (Eds.), Human mental workload. Amsterdam; New York; New York, N.Y., U.S.A.: North-Holland ; Sole distributors for the U.S.A. and Canada, Elsevier Science Pub. Co.

Hill, D. W., Poole, D. C., \& Smith, J. C. (2002). The relationship between power and the time to achieve $\mathrm{VO} 2(\max )$. Medicine and science in sports and exercise, 34(4), 709-714.

Ikuma, L. H., Nussbaum, M. A., \& Babski-Reeves, K. L. (2009). Reliability of physiological and subjective responses to physical and psychosocial exposures during a simulated manufacturing task. International Journal of Industrial Ergonomics, 39(5), 813-820.

Jensen, C. (2003). Development of neck and hand-wrist symptoms in relation to duration of computer use at work. [print]. Scandinavian Journal of Work Environment \& Health, 29(3), 197-205.

Kutner, M. H. (2005). Applied linear statistical models. Boston: McGraw Hill.

Loge, J. H., Ekeberg, Ø., \& Kaasa, S. (1998). Fatigue in the general norwegian population: Normative data and associations. Journal of psychosomatic research, 45(1), 53-65.

Monod, H., \& Scherrer, J. (1965). THE WORK CAPACITY OF A SYNERGIC MUSCULAR GROUP. Ergonomics, 8(3), 329338.

Østensvik, T., Veiersted, K. B., \& Nilsen, P. (2009). A method to quantify frequency and duration of sustained low-level muscle activity as a risk factor for musculoskeletal discomfort. Journal of Electromyography and Kinesiology, 19(2), 283-294.

Pruessner, J. C., Kirschbaum, C., Meinlschmid, G., \& Hellhammer, D. H. (2003). Two formulas for computation of the area under the curve represent measures of total hormone concentration versus time-dependent change. Psychoneuroendocrinology, 28(7), 916-931.

Ricci, J. A., Chee, E., Lorandeau, A. L., \& Berger, J. (2007). Fatigue in the US workforce: prevalence and implications for lost productive work time. Journal of Occupational and Environmental Medicine, 49(1), 1-10.

Schwartz, J. E., Jandorf, L., \& Krupp, L. B. (1993). The measurement of fatigue: a new instrument. Journal of psychosomatic research, 37(7), 753-762.

Shen, J., Barbera, J., \& Shapiro, C. M. (2006). Distinguishing sleepiness and fatigue: focus on definition and measurement. Sleep medicine reviews, 10(1), 63-76.

Snook, S. H., \& Ciriello, V. M. (1991). The design of manual handling tasks: revised tables of maximum acceptable weights and forces. Ergonomics, 34(9), 1197-1213. doi: $10.1080 / 00140139108964855$

Snook, S. H., \& Irvine, C. H. (1969). Psychophysical Studies of Physiological Fatigue Criteria1. Human Factors: The Journal of the Human Factors and Ergonomics Society, 11(3), 291-299. doi: 10.1177/001872086901100311 